\title{
Effects of preweaning nutrient intake in the developing mammary parenchymal tissue
}

\author{
F. Soberon* and M. E. Van Amburgh ${ }^{1}$ \\ *Nutreco USA, 115 Executive Drive, Highland, IL 62249 \\ †Department of Animal Science, Cornell University, Ithaca, NY 14850
}

\begin{abstract}
Historically, mammary gland growth has been considered isometric the first 2 mo of life and then allometric until peripuberty. However, recent work indicated that the mammary gland might be responsive to nutrient intake preweaning. The objectives of this study were to describe the effects of nutrient intake preweaning on mammary gland development and to investigate cell specific proliferation during this phase of development. Twelve dairy heifer calves were fed either a fixed amount of milk replacer (MR; control, $\mathrm{n}=6$ ) or an amount of $\mathrm{MR}$ adjusted for $\mathrm{BW}$ (enhanced, $\mathrm{n}=6$ ). Control calves received a constant amount of a $28 \%$ crude protein, $15 \%$ fat milk MR per day that was equivalent to 2.8 Mcal of metabolizable energy intake per day; enhanced calves received $0.3 \mathrm{Mcal}$ of metabolizable energy intake per kilogram of metabolic body weight (from 4.2 to 8.4 Mcal of metabolizable energy intake per day). All calves had constant access to water and a $22 \%$ crude protein commercial calf starter. Calves were killed at $54 \pm 2$ d. Control calves consumed $32.6 \pm 2.4 \mathrm{~kg}$ of $\mathrm{MR}$ and $6.7 \pm 0.5 \mathrm{~kg}$ of calf starter per calf, whereas the enhanced calves consumed $69.5 \pm 2.4 \mathrm{~kg}$ of $\mathrm{MR}$ and $1.9 \pm 0.5 \mathrm{~kg}$ of calf starter per calf over the $54-\mathrm{d}$ period. Further, to evaluate putative stem cell proliferation, BrdU (5-bromo-2'-deoxyuridine; $5 \mathrm{mg} / \mathrm{kg}$ ) was injected intramuscularly once per day between 12 to $15 \mathrm{~d}$ and again once per day between 24 to $27 \mathrm{~d}$ of life. Initial and final body weight for the control and enhanced treatments were $39.2,61.0,39.7$, and $83.2 \mathrm{~kg}$, respectively. At euthanasia, weights of liver, kidneys, pancreas, whole skinned mammary gland, and mammary parenchyma were measured. The growth rate of each organ was calculated using the concept of allometry as the difference in the change in organ weight as a percentage of body weight. The mammary glands of calves fed the enhanced diet were significantly heavier
\end{abstract}

Received August 4, 2016.

Accepted February 15, 2017.

${ }^{1}$ Corresponding author: mev1@cornell.edu at euthanasia; when mammary parenchymal weight was analyzed, enhanced calves had 5.9 times greater mammary parenchymal mass, indicating the mammary gland was responsive to nutrient intake before weaning. Allometric growth of the mammary gland was initiated preweaning in the calves fed the enhanced treatment. Further characterization of mammary cells that retained BrdU label revealed no significant differences among the tissue slices analyzed between treatments; however, as calves fed the enhanced diet had more mammary parenchymal mass, if the number of labelretaining cells per counted slide were similar between treatments then the enhanced calves had a larger total population of putative mammary stem cells present in the mammary gland.

Key words: mammary gland, preweaning nutrition, growth rate

\section{INTRODUCTION}

Historically, prepubertal mammary development has been described as having 2 distinct phases: isometric and allometric growth (Sinha and Tucker, 1969). Allometry was a term coined by Huxley and Tessier (1936) that describes the ratio between the growth of 2 body parts. When the ratio is equal to 1 , then the growth of the 2 parts is considered isometric. In the case of positive allometric growth, the ratio is greater than 1, which implies a faster growth rate than the part of comparison (Huxley, 1950). Prior to approximately 3 mo of age, the bovine mammary gland has been shown to grow at a similar rate to the body (isometric growth), and then from approximately 3 mo of age to the peripubertal period, positive allometric growth has been observed, (Sinha and Tucker, 1969; Meyer et al. 2006b). In contrast, Brown et al. (2005) and Meyer et al. (2006b) reported that mammary epithelial cell proliferation could be influenced by diet during the preweaning period, but not postweaning. In the data of Meyer et al. (2006b), mammary epithelial cell proliferation assessed by BrdU (5-bromo-2'-deoxyuridine) labeling as a marker for DNA proliferation was allo- 
metric from birth in calves fed higher levels of nutrient intake, suggesting that the previously observed phases of growth in the data of Sinha and Tucker (1969) might have been due to differences in nutrient intake relative to maintenance, at least before weaning. Furthermore, Meyer et al. (2006b) suggested that cells within the mammary gland are nutritionally responsive in the early neonatal period. Given the emerging data describing the effects of early nutrition on long-term productivity (Moallem et al., 2010; Soberon et al., 2012; Soberon and Van Amburgh, 2013), there is a need to understand the factors responsible for this long-term enhancement of productivity.

Further, Ellis and Capuco (2002) and Capuco (2007), using the approach of BrdU label-retaining cells (LRC), described the identification of a primary proliferative cell population in the mammary parenchyma, considered a putative stem cell population. Capuco (2007) indicated this population was mixed, with some cells being estrogen-sensitive progenitors, and this might provide some insights into the mechanism behind the observation that increased nutrient intake and higher ADG in preweaned calves results in greater milk yield through the growth of more progenitor cells during the early postnatal development of the mammary gland. Increasing the number of putative stem cells, if they are progenitor cells, would provide one possible mechanism for greater milk yield through greater cell production of secretory cells in the mammary gland at the onset of lactation. For this experiment, our hypothesis was that mammary cells and the mammary gland in general are nutrient-responsive during the preweaning phase of development; thus, proliferation can be altered during this period as an outcome of specific cells types. Therefore, the objectives of our study were to determine the effects of the preweaning feeding program on organ size, mammary gland development, and putative stem cell proliferation in dairy calves using the LRC approach.

\section{MATERIALS AND METHODS}

All protocols involving the use of animals were reviewed and approved by the Cornell University Institutional Animal Care and Use Committee (Protocol number 2009-0120). Calves for this study were born between July 24, 2010, and August 1, 2010. Twelve Holstein heifer calves from the Cornell Research Farm (Harford, NY) were randomly assigned at birth to 1 of 2 treatments (TRT). All calves received $4 \mathrm{~L}$ of colostrum within $1 \mathrm{~h}$ of birth and $2 \mathrm{~L}$ after another $12 \mathrm{~h}$. Calves assigned to the enhanced TRT were fed $0.3 \mathrm{Mcal}$ of ME intake per kilogram of metabolic BW $\left(\mathrm{BW}^{0.75}\right)$ in 3 daily feedings; the amount of milk replacer (MR) was adjusted weekly according to changes in BW. Daily
Table 1. Milk replacer and starter grain chemical composition as reported by manufacturer

\begin{tabular}{lcc}
\hline Analysis (DM basis) & Milk replacer $^{1}$ & Starter grain $^{2}$ \\
\hline CP, \% & 28.5 & 22.0 \\
Crude fat, \% & 15.0 & 4.3 \\
NDF, \% & 0.2 & 33.1 \\
Calcium, \% & 1.0 & 1.6 \\
Phosphorus, \% & $>0.6$ & 1.0 \\
Vitamin A, IU/g & $>16.5$ & 43.1 \\
Vitamin D , IU/g & $>5.5$ & $\mathrm{NA}^{3}$ \\
Vitamin E, IU/kg & $>110.3$ & 197.0 \\
Gross energy, Mcal/kg & 5.1 & 1.8 \\
\hline
\end{tabular}

${ }^{1}$ Excelerate, Milk Specialties Inc., Carpentersville, IL.

${ }^{2}$ Cargill Inc., Minneapolis, MN.

${ }^{3} \mathrm{NA}=$ not available.

amounts of energy received by each calf increased from 4.2 to $8.4 \mathrm{Mcal}$ of ME intake energy per day. Calves in the control group were fed 2.8 Mcal of ME per day in 2 daily feedings throughout the study; this TRT was designed to reflect the previous industry-standard preweaning MR feeding rates. All calves were fed a milk replacer containing $28 \%$ protein and $15 \%$ fat (Excelerate, Milk Specialties Inc., Carpentersville, IL; Table 1). Milk replacer refusals were recorded at each feeding. Starting on d 18, calves were offered a commercially available starter grain (22\% CP, Cargill Inc., Minneapolis, MN; Table 1); starter grain consumption was recorded daily. Fresh water was available at all times.

All calves were housed in individual hutches bedded with sawdust throughout the study. Body weights and hip heights of each calf were measured weekly $1 \mathrm{~h}$ after the morning feeding. Calves received milk replacer until they were killed at $54 \mathrm{~d}$. All calves received 8 daily intravenous injections of BrdU (5-bromo,2'-deoxyuridine; Sigma-Aldrich, Saint Louis, MO) at a concentration of $5 \mathrm{mg} / \mathrm{kg}$ of BW to label DNA in putative stem cells (Smith, 2005; Capuco, 2007; Huderson et al., 2011); injections were given from d 12 to 15 and 24 to 27 of study. Two injection periods were used to ensure the label was available through the early growth phase of the study. Daniels et al. (2009) injected BrdU for 1 period and Meyer et al. (2006b) used only 1 injection at the time of euthanasia; however, little information exists concerning mammary proliferation throughout the preweaning period, and we wanted to ensure we could capture any possible changes. Therefore, we chose to provide the label over 2 periods, as the putative stem cells should be the only cells that retain the label.

On the day of euthanasia, calves were fed at 0700 $\mathrm{h}$, weighed, and loaded for transport to the Cornell University abattoir (Ithaca, NY). Calves were killed by stunning with a captive bolt, followed directly by exsanguination. Immediately after exsanguination, the mammary gland was removed from the body and 
skinned; the skinned mammary gland was weighed and the mammary gland was then sectioned at the midline and each half was weighed independently. The mammary parenchymal tissue was dissected by visual identification of tissue structure, and the parenchymal mass of each quarter was individually weighed. Mammary development in 1 calf from the control treatment was so small that it could not be dissected from the mammary fat pad; thus, her data were not included. After weighing, a representative sample of mammary parenchyma contiguous to the mammary fat pad from each quarter was fixed overnight in $10 \%$ paraformaldehyde in PBS at pH 7.2 (Fisher Scientific, Pittsburgh, PA). After 24 $\mathrm{h}$, tissue samples were moved to $70 \%$ ethanol until they were embedded for immunohistochemistry. The ovaries in each calf were visually inspected to confirm their presence and assess reproductive viability. The liver, pancreas, and kidneys were also removed and weights were recorded for each calf. All proliferation calculations and all comparisons were made on fresh tissue measurements. The primary objective of our study was to evaluate LRC in the mammary gland; however, after killing the first 4 calves, differences were observed in other organ sizes, which led us to collect additional tissue weights and samples in subsequent calves.

\section{Immunohistochemistry}

Immunohistochemistry procedures were performed according to Capuco et al. (2001). In brief, slides containing tissue were deparaffinized in xylene and rehydrated in a graded series of ethanol. Tissue sections were quenched with $3 \% \mathrm{H}_{2} \mathrm{O}_{2}$ in PBS for $10 \mathrm{~min}$ and then washed in PBS $(3 \times 2 \mathrm{~min})$. Slides were microwaved at high power $(650 \mathrm{~W})$ in $400 \mathrm{~mL}$ of $10 \mathrm{~m} M$ citrate buffer ( $\mathrm{pH} 6.0)$ in a covered glass staining dish for $5 \mathrm{~min}$, remained undisturbed for $5 \mathrm{~min}$, and then were microwaved for an additional 5 min. Slides remained in the buffer for a 30-min cooling period. Tissue sections were washed in PBS $(3 \times 2 \mathrm{~min})$ and blocked with $5 \%$ solution of goat serum in PBS (30 min). Slides were incubated with BrdU monoclonal antibody (clone BMC 9318, Boehringer Mannheim, Roche Diagnostics, Basel Switzerland), diluted to $1: 250$, added at a concentration of $4 \mu \mathrm{g} / \mathrm{mL}$, and incubated at $37^{\circ} \mathrm{C}$ for $1.5 \mathrm{~h}$. Slides were then washed in PBS $(3 \times 5 \mathrm{~min})$. Second antibody (goat anti-mouse IgG, Sternberger Monoclonals Inc., Lutherville, MD) containing 1\% normal goat serum and $2 \%$ normal calf serum in PBS was added and incubated at room temperature for $30 \mathrm{~min}$. The advidin-biotin complex system was used for signal amplification with a 15-min incubation. Colorization was performed using the AEC chromogen substrate solution (Invitrogen,
Camarillo, CA) for 30 min. Slides were then counterstained in hematoxylin, dehydrated, and then mounted with Permaslip (Alban Scientific Inc., St. Louis, MO). Slides were observed with a light microscope using bright field illumination, areas of epithelial cells were identified using a $10 \times$ lens, and then a $40 \times$ lens was used to photograph the area; all photographs were taken by the same person. Pictures were taken from random areas within the mammary epithelium and all recorded images were used for the analysis. Number of images per slide varied depending on tissue size and abundance of epithelium within the tissue, but averaged 7.1 images per calf. Cell counts were made with ImageJ Software (National Institutes of Health; https://imagej.nih.gov/ ij/) using 8-bit conversions of each photograph. The background was subtracted and the image adjusted for contrast and the cells counted by the software. The BrdU-positive epithelial cells were counted manually before modifying the image for automatic counting of total number of epithelial cells, counts were recorder per slide and image and then the number of LRC were divided into the total number of epithelial cells and analyzed by treatment (Figure 1).

\section{Statistical Analysis}

Individual growth rates for BW gain were determined by regression of individual calf BW throughout the 54-d period, and a similar approach was used for hip height. Mammary and other organ growth data were analyzed by comparison of the tissue weight at euthanasia by treatment and the model used was

$$
Y_{i}=S_{i}+E_{i}
$$

where $Y_{i}$ is the dependent, continuous variable; $S_{i}=$ the effect of treatment; and $E_{i}=$ the residual error of the ith ADG. Calf identification was treated as a random variable.

Mammary BrdU labeling was analyzed using the number of LRC measured per total cells per slide. Each slide was evaluated and every slide was used in the analysis, the model used was

$$
Y_{i}=S_{i}+E_{i}
$$

where $Y_{i}$ is the dependent, variable; $S_{i}=$ the effect of treatment (number of LRC/total cell count per slide); and $E_{i}=$ the residual error of the $i$ th treatment. Calf identification was treated as a random variable.

Dry matter intake was analyzed using the model

$$
Y_{i}=S_{i}+E_{i}
$$



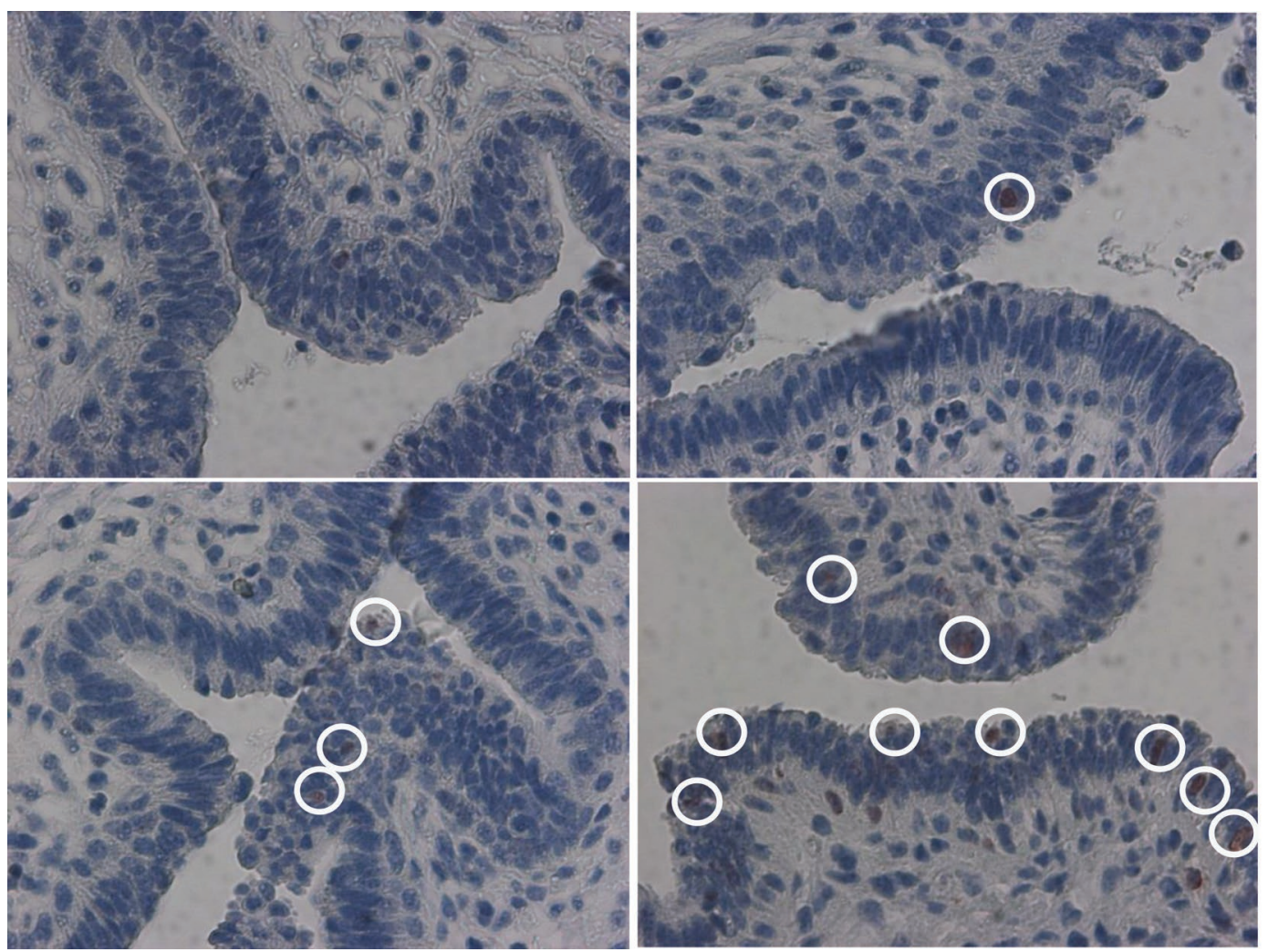

Figure 1. Example photographs of mammary tissue from the study to evaluate BrdU (5-bromo,2'-deoxyuridine; Sigma-Aldrich, St. Louis, MO) label-retaining cells in Holstein heifer calves fed 2 levels of nutrient intake and treated with BrdU between 12 and 15 d of study and again between 24 and $27 \mathrm{~d}$ of study and killed at d 54. White circles show BrdU-labeled cells. Color version available online.

where $Y_{i}$ is the dependent, continuous variable; $S_{i}=$ the effect of treatment; and $E_{i}=$ the residual error of the $i$ th calf. Calf identification was treated as a random variable.

Data were analyzed using the PROC MIX mixed procedures of SAS 9.2 (SAS Inst. Inc., Cary, NC), and the mixed procedure was used to help account for the unbalanced variance due to incomplete and unbalanced data due to missing mammary observations. Significance was declared at $P<0.05$.

\section{RESULTS AND DISCUSSION}

Calves fed the enhanced treatment had higher MR intakes but lower starter grain intakes than control calves $(69.5$ and 1.9 vs. 32.6 and $6.7 \mathrm{~kg}$ of DMI from MR and starter grain for enhanced and control, respectively; $P<0.01$; Table 2, Figure 2). Similarly, calves in the enhanced treatment exhibited higher ADG than control calves throughout the study $(0.82$ vs. $0.39 \mathrm{~kg}$ for enhanced and control, respectively; $P<0.01$ ); Enhanced calves also had higher gains in hip height throughout the study $(0.31$ vs. $0.18 \mathrm{~cm} / \mathrm{d}$ for enhanced and control, respectively; $P<0.01$; Table 2). At the time of euthanasia, calves were $54 \pm 2 \mathrm{~d}$ of age and the enhanced calves were $22.2 \mathrm{~kg}$ or $36.4 \%$ heavier than control calves $(P<0.01$; Table 2 , Figure 3$)$. Calves in the enhanced group tended to be $5.2 \mathrm{~cm}$ or $6 \%$ taller than control calves $(P=0.08)$. The current growth recommendation for dairy calves is to double the birth weight by weaning (Van Amburgh et al., 2008), and the calves in the enhanced group achieved this target at 2.1 times their birth weight, whereas the control calves were only 1.6 times their birth weight at the time of weaning.

In this study, the enhanced calves received an average 3.1 Mcal more energy per day than control calves (5.9 vs $2.8 \mathrm{Mcal} / \mathrm{d}$ for enhanced and control; Table 2). The energy requirements were calculated using $\mathrm{BW}$ and ambient temperatures (NRC, 2001), and then the calculated energy for maintenance was subtracted from the corresponding energy intakes. This resulted in 3.75 Mcal of ME above maintenance for the enhanced TRT calves and only 0.89 Mcal of ME above maintenance for control calves. At the time of euthanasia, enhanced calves were $36.4 \%$ heavier than control calves (Table 2). The weight of the pancreas from all calves was similar at $54 \mathrm{~d}$ of age (Table 3), suggesting that organs such 


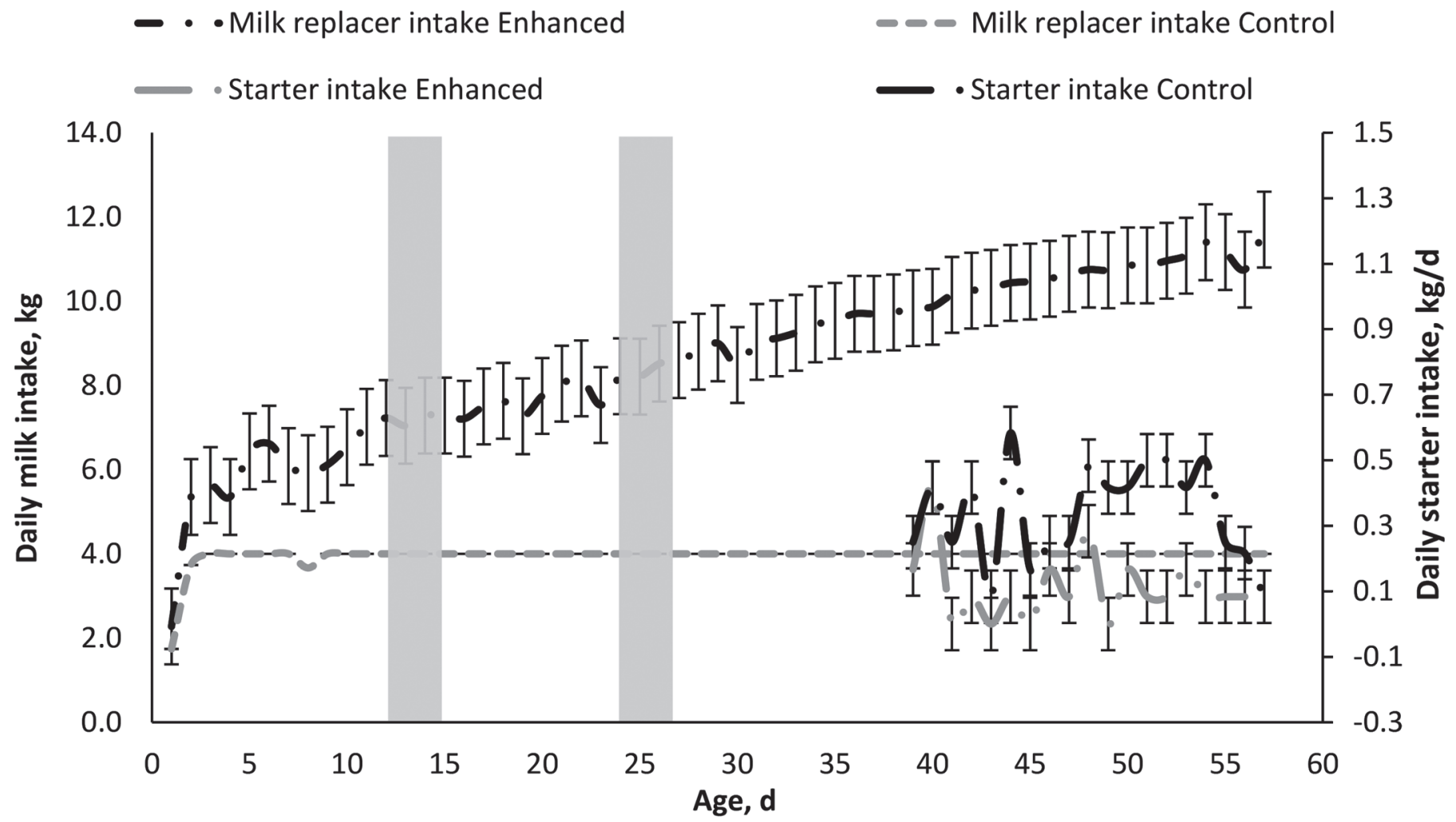

Figure 2. Daily intake data of milk replacer and calf starter and times of BrdU (5-bromo,2'-deoxyuridine; Sigma-Aldrich, St. Louis, MO) administration for calves fed $2.8 \mathrm{Mcal}$ of energy intake/d of milk replacer (control; $\mathrm{n}=6$ ) or calves fed $0.3 \mathrm{Mcal}$ of energy intake/kg of metabolic $\mathrm{BW}\left(\mathrm{BW}^{0.75}\right)$ of milk replacer, updated weekly as BW increased (enhanced; $\mathrm{n}=6$ ). Means per treatment and SD are shown.

as the pancreas grow at a steady rate, independent of nutrient intake during the first $54 \mathrm{~d}$ of life. In contrast, the kidneys, after removing all visible fat, of enhanced calves were heavier than the kidneys of control calves (Table 3). When analyzed as a percentage of BW, however, we found no differences between enhanced and control, suggesting that the kidneys grow at an isometric rate with $\mathrm{BW}$ irrespective of nutrition.

The livers of enhanced calves were heavier than the livers of control calves (2.8 vs. $2.2 \%$ of BW for enhanced and control, respectively; $P<0.01$; Table 3 ). This difference in liver weight was expected, given that

Table 2. Body weight, hip height at birth and at euthanasia, ADG, average change in hip height, and intake data for calves fed 2.8 Mcal of energy intake/d (control; $\mathrm{n}=6$ ) or calves fed 0.3 Mcal of energy intake $/ \mathrm{kg}$ of metabolic BW $\left(\mathrm{BW}^{0.75}\right)$, updated weekly as BW increased (enhanced; $\mathrm{n}=6$ )

\begin{tabular}{lcccr}
\hline Item & Control & Enhanced & SE & $P$-value \\
\hline Birth weight, kg & 39.2 & 39.7 & 2.5 & 0.90 \\
Hip height at birth, cm & 78.3 & 76.3 & 2.4 & 0.56 \\
Weight at euthanasia, kg & 61.0 & 83.2 & 3.9 & $<0.01$ \\
Hip height at euthanasia, cm & 87.3 & 92.5 & 1.9 & 0.08 \\
Age at euthanasia, d & 54.3 & 54.0 & 0.9 & 0.80 \\
ADG from birth to 54 d, kg/d & 0.39 & 0.82 & 0.03 & $<0.01$ \\
Average change in hip height, cm/d & 0.18 & 0.31 & 0.02 & $<0.01$ \\
Total milk replacer intake, kg of DM & 32.6 & 69.5 & 2.4 & $<0.01$ \\
Average milk replacer intake, kg/d of DM & 0.6 & 1.3 & 0.04 & $<0.01$ \\
Total starter grain intake in 36 d, kg as fed & 6.7 & 1.9 & 0.5 & $<0.01$ \\
Total energy intake from milk/d, Mcal, IE ${ }^{1}$ & 2.8 & 5.9 & 0.17 & $<0.01$ \\
Maintenance requirements, ${ }^{2} \mathrm{Mcal} / \mathrm{d}$ & 1.9 & 2.2 & 0.08 & 0.02 \\
Mcal above maintenance, Mcal/d & 0.9 & 3.8 & 0.11 & $<0.01$ \\
\hline
\end{tabular}

${ }^{1} \mathrm{IE}=$ intake energy.

${ }^{2}$ Energy requirements were calculated using BW and ambient temperature according to equations from the $\operatorname{NRC}(2001)$. 


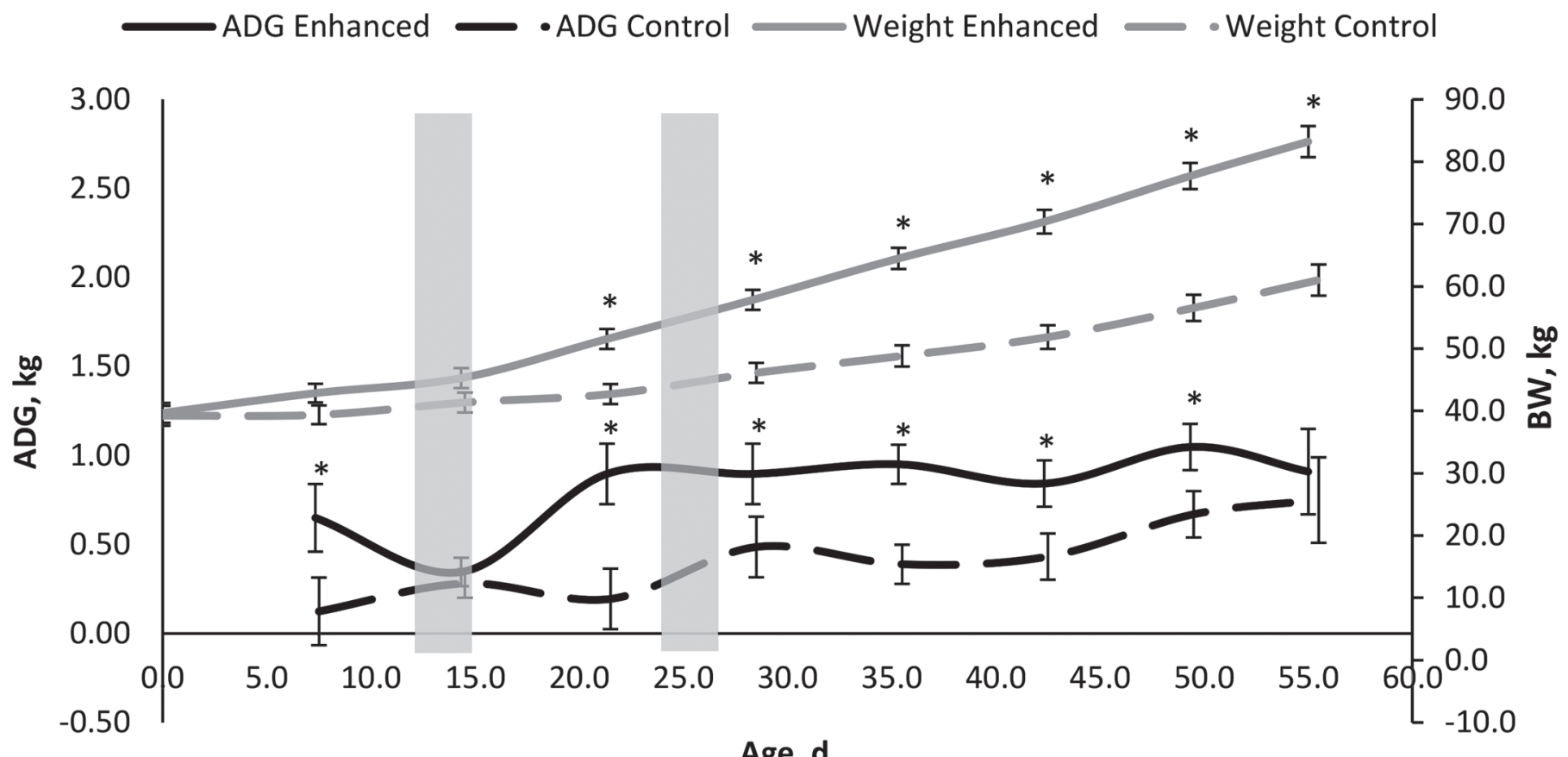

Age, $d$

Figure 3. Weekly BW, ADG by week, and times of BrdU (5-bromo,2'-deoxyuridine; Sigma-Aldrich, St. Louis, MO) administration for calves fed 2.8 Mcal of energy intake/d of milk replacer (control; $\mathrm{n}=6$ ) or calves fed 0.3 Mcal of energy intake/kg of metabolic BW (BW ${ }^{0.75}$ ) of milk replacer, updated weekly as BW increased (enhanced; $\mathrm{n}=6$ ). Means per treatment and SD shown. Weekly values with an asterisk $(*)$ differ $(P<0.02)$.

liver size is dynamic and responsive to nutrient intake (Diaz et al., 2001), even when analyzed as a percentage of BW. Diaz et al. (2001) observed similar results where the livers of calves fed higher nutrient intakes were $27 \%$ larger than restricted calves at similar BW; more recently, Geiger et al. (2016) observed similar responses on liver growth due to the effect of greater nutrient intake.

Similarly, the mammary glands of calves in the enhanced group were also heavier than the mammary glands of control calves (Figure 4). When analyzed as a percentage of BW, the mammary glands of enhanced calves were 3.4 times heavier than those of control calves $(P<0.01)$, similar to that observed in Meyer et al. (2006a), where the mammary glands of calves fed for higher nutrient intake weighed 2.3 times more than that of calves fed restricted nutrients when comparing calves of similar age. Further, the parenchymal mass of the mammary glands of enhanced calves weighed 5.9 times more than the mammary parenchymal mass of control calves (6.48 vs. $1.1 \mathrm{~g}$ for enhanced and control, respectively; $P<0.01$; Table 3 , Figure 4). Meyer et

Table 3. Fresh organ weights $(\mathrm{g})$ and as a percentage of BW for calves fed 2.8 Mcal of energy intake/d (control; $\mathrm{n}=6$ ) or calves fed $0.3 \mathrm{Mcal}$ of energy intake $/ \mathrm{kg}$ of metabolic $\mathrm{BW}\left(\mathrm{BW}^{0.75}\right.$; enhanced; $\left.\mathrm{n}=6\right)$ from birth until death at $54 \mathrm{~d}$

\begin{tabular}{lrrrr}
\hline Item & Control & Enhanced & SE & $P$-value \\
\hline Pancreas, ${ }^{1}$ g & 32.90 & 29.47 & 4.39 & 0.61 \\
Pancreas as \% of BW & 0.06 & 0.04 & 0.01 & 0.11 \\
Liver, kg & 1.35 & 2.35 & 0.82 & $<0.01$ \\
Liver as \% of BW & 2.23 & 2.84 & 0.09 & $<0.01$ \\
Kidney, g & 183.60 & 319.72 & 33.29 & 0.02 \\
Kidney as \% of BW & 0.30 & 0.38 & 0.03 & 0.09 \\
Whole mammary gland, g & 75.48 & 337.58 & 29.14 & $<0.01$ \\
Mammary gland as \% of BW & 0.12 & 0.41 & 0.03 & $<0.01$ \\
Mammary parenchyma, g & 1.10 & 6.48 & 1.00 & $<0.01$ \\
Mammary parenchyma as \% of mammary gland & 1.35 & 1.90 & 0.37 & 0.30 \\
Mammary parenchyma as \% of BW & 0.002 & 0.008 & 0.001 & $<0.01$ \\
\hline
\end{tabular}

${ }^{1}$ Pancreas samples were collected for only 4 calves per treatment. 


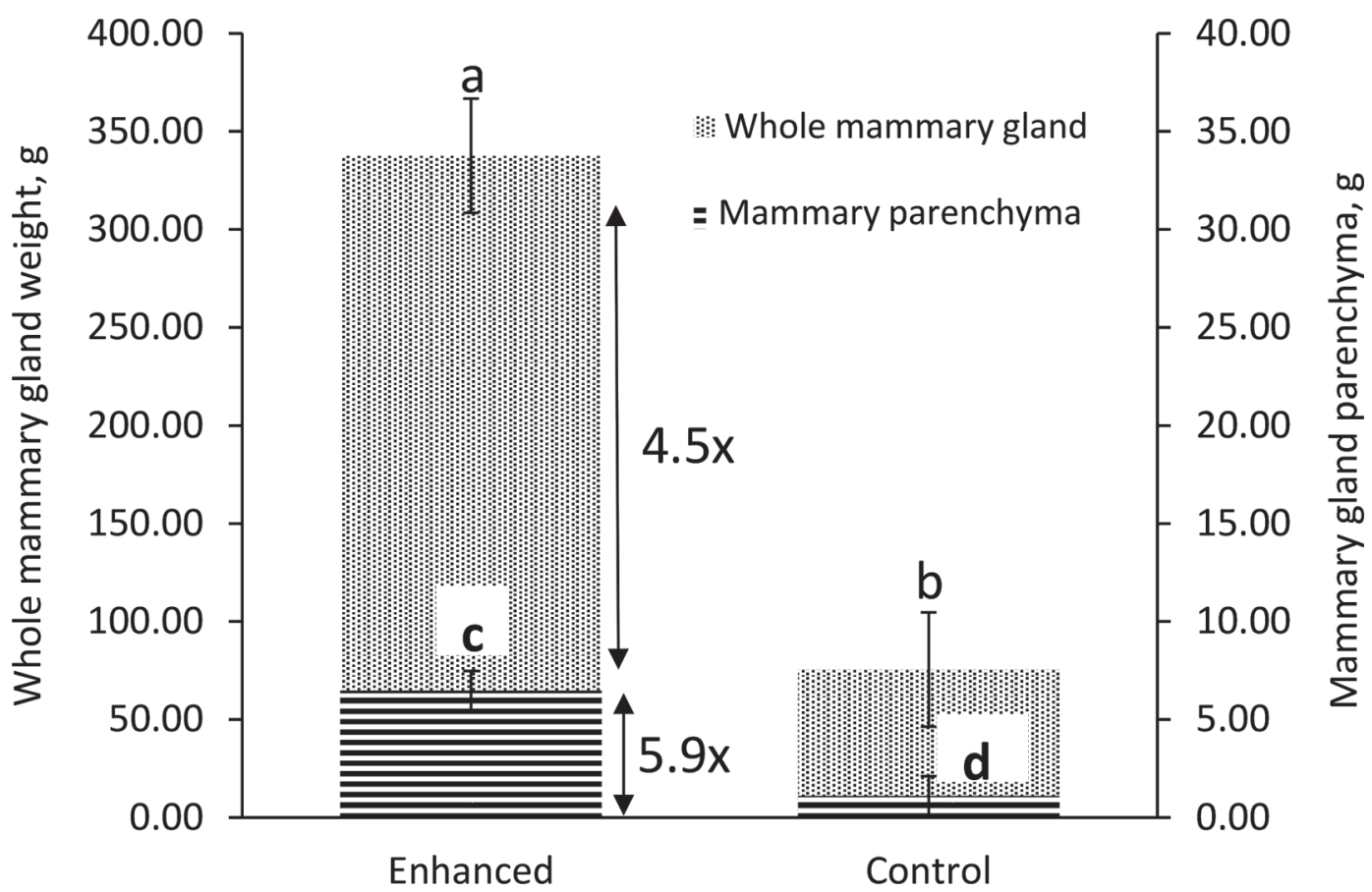

Figure 4. Weights of the whole skinned mammary gland and weight of isolated mammary parenchyma for calves fed 2.8 Mcal of energy intake/d (control; $\mathrm{n}=6$ ) or calves fed $0.3 \mathrm{Mcal}$ of energy intake $/ \mathrm{kg}$ of metabolic $\mathrm{BW}\left(\mathrm{BW}^{0.75}\right.$; enhanced; $\left.\mathrm{n}=6\right)$ from birth until euthanasia at 54 d. Means and SD are shown. Columns with different letters $(\mathrm{a}-\mathrm{d})$ differ $(P<0.05)$.

al. (2006b) observed that the mammary parenchymal mass of calves fed higher nutrient intakes was 2.1 times heavier than restricted calves at similar age. In addition, Brown et al. (2005) compared the mammary tissue of 8 -wk-old heifer calves grown at 2 different rates of gain and observed that the mammary parenchymal tissue of heifers fed more nutrients was 3.75 times heavier than that of calves fed a restricted diet. When compared as grams of mammary parenchyma per $100 \mathrm{~kg}$ of $\mathrm{BW}$, the mammary parenchyma tissue was 3.3 times heavier than that of the restricted calves (Brown et al., 2005).

When comparing calves grown at different rates of gain and evaluating mammary parenchymal tissue at similar BW, heifers offered diets restricted in nutrient intake have heavier mammary parenchyma tissue, which can be attributed to a constant daily growth of the mammary parenchyma tissue, as those calves are older in age at the same weight (Meyer et al., 2006a). However, this pattern of growth appears to be modified due to nutrient intake in calves throughout the first 2 mo of life (Brown et al., 2005; Meyer et al., 2006a; Geiger et al., 2016).

In response to an increased nutrient intake above maintenance during preweaning, the mammary parenchyma appears to shift to an allometric phase of growth immediately after birth; this is in contrast to the origi- nal data of Sinha and Tucker (1969) and suggests the calves used in that study were not allowed to consume high levels of nutrients above maintenance, as there is no description of the preweaning period available for those calves. In our study, the mammary parenchyma demonstrated the greatest response to increased energy intake of all the major organs measured. These findings aligned with other studies that observed increased proliferation of mammary parenchyma before weaning of calves fed higher levels of nutrient intake (Brown et al. 2005; Meyer et al., 2006b; Geiger et al., 2016); thus, it appears that in early postnatal life, mammary development can be modified due to the level of nutrient intake above maintenance.

In the current study, the mammary parenchymal mass as well as the liver and the whole mammary gland grew at an allometric rate when compared with the rest of the body during the preweaning period. Furthermore, when the mammary parenchymal mass was analyzed as a percent of the whole mammary gland, we found no differences among enhanced and control treatments. This would suggest that, during the preweaning stage, both the mammary parenchymal mass as well as the fat pad of the mammary glands are equally responsive to nutrient intake. This is consistent with the observations of Brown et al. (2005), Meyer et al. (2006a), and Geiger et al. (2016). 
Within the mammary parenchyma evaluated for immunohistochemistry, no differences were observed between treatments for BrdU-positive cells. For the control calves, we noted $0.52 \pm 0.46 \mathrm{LRC}$ per slide out of $367 \pm 142$ (mean $\pm \mathrm{SD}$ ) total mammary epithelial cells per slide; for the enhanced calves we observed $0.82 \pm 0.78$ LRC per slide out of $380 \pm 124$ (mean \pm SD) total mammary epithelial cells per slide $(P=0.82$ for LRC and $P=0.63$ for cell number). The BrdUpositive cells were uniformly distributed throughout all tissue samples, although a couple calves on both treatments did not have any LRC, which contributed the high standard deviation. As stated earlier, 1 calf on the control treatment did not have enough tissue to dissect, thus that calf was not represented in the data. The BrdU was given to the calves twice, at approximately 14 and $25 \mathrm{~d}$ of study, which was very early in the growth period relative to the euthanasia date of $54 \mathrm{~d}$. Thus, any LRC should be considered related to the putative stem cell population described by Capuco (2007). Comparing the results of the LRC observed by Capuco (2007), 0.24\%, the percent of LRC for the control treatment calves was $0.14 \%$ whereas the enhanced calves was $0.22 \%$; thus, the LRC were lower than previously described for the control calves but similar for the enhanced calves. Considering the significant difference in epithelial tissue mass among the enhanced and the control calves, the total number of positive cells within the mammary gland would be approximately 6 times greater for the enhanced treatment. Future work should attempt to evaluate individual regions of the mammary parenchyma independently for immunohistochemistry analysis to better determine differences among nutritional treatments. The amount of tissue at this stage of development was relatively small, making it difficult if not impossible to use the tissue to make other comparisons, such as those conducted by Meyer et al. (2006a,b) and Geiger et al. (2016). Daniels et al. (2009) followed a similar approach to that described in the present study, but administered the BrdU at $32 \mathrm{~d}$ of life and observed no differences in BrdU label-retaining cells. In contrast to the current study, Daniels et al. (2009) did not observe differences in mammary parenchymal mass at the time of euthanasia at $64 \mathrm{~d}$. The composition of the milk replacers offered by Daniels et al. (2009) was different for each treatment and could have contributed to the differences in responsiveness of the mammary parenchymal mass.

Inconsistencies still exist in the observed responses among studies, and that is a justification for further investigation. For example, the implication from our study is that, with no real difference in BrdU incorporation, there was no difference in parenchymal DNA per cell among the treatments; however, due to differ- ences in total parenchymal mass, more total DNA was found, which would be consistent with recent data from Geiger et al. (2016). However, the observation of Meyer et al. (2006b) would suggest an opportunity to enhance DNA content of the parenchyma, especially because there was a significant increase in BrdU incorporation in calves fed greater nutrient intake above maintenance.

A consideration for exploring differences among studies was to recognize that previous studies reporting isometric growth before weaning did not provide the calf with sufficient nutrient intake from milk or milk replacer to stimulate a similar type of growth response in the mammary gland to what was observed in our study. It appears that in the neonatal period, the mammary parenchyma, and most likely very specific cells (Ellis and Capuco, 2002) are nutritionally responsive. In the study by Daniels et al. (2009), the authors attempted to identify the label-retaining cells using a similar protocol to the one used in the current study, but gave the BrdU injections at $32 \mathrm{~d}$ of life for $4 \mathrm{~d}$. Daniels et al. (2009) observed differences in labeling by region of the mammary gland, with the highest degree of labeling toward the gland cistern, but no differences among dietary treatments. The timing of nutritional sensitivity of such populations of cells has not been determined, and although animals in our study and Daniels et al. (2009) were both about 2 mo old at the time of analysis, our study attempted to determine the effect of nutrition on mammary development at an earlier age by starting BrdU labeling on d 12. Due to a difference in the sampling technique and the low amount of tissue available at this stage of development, the current study did not evaluate differences in labeling by region of the mammary parenchyma. However, the developmental response was significant and a nutritionally sensitive cell type was responsible for the proliferation of the mammary parenchyma. This proliferation of the putative stem cells might be part of the mechanism stimulating greater lactation yield of the calf once they reach lactation (Moallem et al., 2010; Soberon et al., 2012; Soberon and Van Amburgh, 2013), but there is much more work to do to make any definitive link among mammary cells at this stage of development and future milk yield. Identification of the specific cells and the factors stimulating this proliferation is warranted.

\section{CONCLUSIONS}

The mammary gland of dairy calves is responsive to nutrient intake during the preweaning stage, and this differs from postweaning mammary gland development. The allometric stage of growth in the mammary gland appears to begin at birth if sufficient nutrients from milk or milk replacer are provided to the neonatal calf. 
It is still to be determined if the responsiveness of the mammary gland is due to a specific group of cells, or to a generalized response to nutrients. However, a better understanding of the effect of early life nutrient intake on mammary development and overall development on future milk production deserves further investigation.

\section{ACKNOWLEDGMENTS}

We gratefully acknowledge Milk Specialties Global (Eden Prairie, MN) and Land O'Lakes (Shoreview, MN) support of this work, Debbie Ross (Cornell University) for technical support, the staff of the Teaching and Research Farm (Harford, NY), as well as Melanie Soberon (Cornell University), Ryan Higgs (Cornell University), Cao Zhijun (China Agricultural University, Beijing, China), Samuel Fessenden (Cornell University), and Brianna Pomeroy (Cornell University) for their help and support of this study.

\section{REFERENCES}

Brown, E. G., M. J. VandeHaar, K. M. Daniels, J. S. Liesman, L. T. Chapin, J. W. Forrest, R. M. Akers, R. E. Pearson, and M. S. Weber Nielsen. 2005. Effect of increasing energy and protein intake on mammary development in heifer calves. J. Dairy Sci. 88:595-603.

Capuco, A. V. 2007. Identification of putative bovine mammary epithelial stem cells by their retention of labeled DNA strands. Exp. Biol. Med. (Maywood) 232:1381-1390.

Capuco, A. V., D. L. Wood, R. Baldwin, K. Mcleod, and M. J. Paape. 2001. Mammary cell number, proliferation, and apoptosis during a bovine lactation: relation to milk production and effect of bST. J. Dairy Sci. 84:2177-2187.

Daniels, K. M., A. V. Capuco, M. L. McGilliard, R. E. James, and R. M. Akers. 2009. Effects of milk replacer formulation on measures of mammary growth and composition in Holstein heifers. J. Dairy Sci. 92:5937-5950.

Diaz, M. C., M. E. Van Amburgh, J. M. Smith, J. M. Kelsey, and E. L. Hutten. 2001. Composition of growth of Holstein calves fed milk replacer from birth to 105 kilogram body weight. J. Dairy Sci. 84:830-842.
Ellis, S., and A. V. Capuco. 2002. Cell proliferation in bovine mammary epithelium: Identification of the primary proliferative cell population. Tissue Cell 34:155-163.

Geiger, A. J., C. L. M. Parsons, and R. M. Akers. 2016. Feeding higher plane of nutrition and providing exogenous estrogen increases mammary gland development in Holstein heifer calves. J. Dairy Sci. 99:7642-7653.

Huderson, B. P., B. T. Velayudhan, R. E. Pearson, S. E. Ellis, and R. M. Akers. 2011. Effect of exogenous somatotropin in Holstein calves on mammary gland composition and proliferation. J. Dairy Sci. 94:5005-5016.

Huxley, J. 1950. Relative growth and form transformation. Pages 465-469 in Proc. R. Soc. Lond. Biol. Sci., vol. 137. Royal Society, London, UK.

Huxley, J., and G. Teissier. 1936. Terminology of relative growth rates. Nature 137:780-781.

Meyer, M. J., A. V. Capuco, D. A. Ross, L. M. Lintault, and M. E. Van Amburgh. 2006a. Developmental and nutritional regulation of the prepubertal heifer mammary gland: I. Parenchyma and fat pad mass and composition. J. Dairy Sci. 89:4289-4297.

Meyer, M. J., A. V. Capuco, D. A. Ross, L. M. Lintault, and M. E. Van Amburgh. 2006b. Developmental and nutritional regulation of the prepubertal bovine mammary gland: II. Epithelial cell proliferation, parenchymal accretion rate, and allometric growth. J. Dairy Sci. 89:4298-4304.

Moallem, U., D. Werner, H. Lehrer, M. Zachut, L. Livshitz, S. Yakoby, and A. Shamay. 2010. Long-term effects of ad libitum whole milk prior to weaning and prepubertal protein supplementation on skeletal growth rate and first-lactation milk production. J. Dairy Sci 93:2639-2650.

NRC. 2001. Nutrient Requirements of Dairy Cattle. 7th rev. ed. Natl. Acad. Press, Washington, DC.

Sinha, Y. N., and H. A. Tucker. 1969. Mammary development and pituitary prolactin level of heifers from birth through puberty and during the estrous cycle. J. Dairy Sci. 52:507-512.

Smith, G. H. 2005. Label-retaining epithelial cells in mouse mammary gland divide asymmetrically and retain their template DNA strand. Development 132:681-687.

Soberon, F., E. Raffrenato, R. W. Everett, and M. E. Van Amburgh. 2012. Pre-weaning milk replacer intake and effects on long term productivity of Dairy calves. J. Dairy Sci. 95:783-793.

Soberon, F., and M. E. Van Amburgh. 2013. The effect of nutrient intake from milk or milk replacer of pre-weaned dairy calves on lactation milk yield as adults: a meta-analysis of current data. J. Anim. Sci. 91:706-712.

Van Amburgh, M. E., E. Raffrenato, and F. Soberon. 2008. Early life management and long-term productivity of dairy calves. Pages 185-192 in Proc. Cornell Nutr. Conf., vol. 70. Syracuse, NY. Dept. of Animal Science, Cornell Univ., Ithaca, NY. 